This item was submitted to Loughborough's Research Repository by the author.

Items in Figshare are protected by copyright, with all rights reserved, unless otherwise indicated.

\title{
The use of volumetric projections in Digital Human Modelling software for the identification of large goods vehicle blind spots
}

PLEASE CITE THE PUBLISHED VERSION

http://dx.doi.org/10.1016/j.apergo.2015.10.013

PUBLISHER

(c) Elsevier

VERSION

AM (Accepted Manuscript)

\section{PUBLISHER STATEMENT}

This work is made available according to the conditions of the Creative Commons Attribution-NonCommercialNoDerivatives 4.0 International (CC BY-NC-ND 4.0) licence. Full details of this licence are available at: https://creativecommons.org/licenses/by-nc-nd/4.0/

\section{LICENCE}

CC BY-NC-ND 4.0

\section{REPOSITORY RECORD}

Summerskill, Steve, Russell Marshall, Sharon Cook, James Lenard, and John H. Richardson. 2015. "The Use of Volumetric Projections in Digital Human Modelling Software for the Identification of Large Goods Vehicle Blind Spots". Loughborough University. https://hdl.handle.net/2134/19581. 


\title{
The use of volumetric projections in Digital Human Modelling software for the identification of large goods vehicle blind spots
}

\author{
Steve Summerskill, Russell Marshall, Sharon Cook, James Lenard, John Richardson \\ Loughborough Design School \\ Loughborough University \\ Loughborough \\ Leicestershire \\ LE11 3TU \\ S.J.Summerskill2@lboro.ac.uk- Corresponding author (Tel: 01059228313 Fax: 01509 233999) \\ R.Marshall@lboro.ac.uk \\ S.E.Cook@lboro.ac.uk \\ i.a.lenard@lboro.ac.uk \\ j.h.richardson@lboro.ac.uk
}

\begin{abstract}
The aim of the study is to understand the nature of blind spots in the vision of drivers of Large Goods Vehicles caused by vehicle design variables such as the driver eye height, and mirror designs. The study was informed by the processing of UK national accident data using cluster analysis to establish if vehicle blind spots contribute to accidents. In order to establish the cause and nature of blind spots six top selling trucks in the UK, with a range of sizes were digitized and imported into the SAMMIE Digital Human Modelling (DHM) system. A novel CAD based vision projection technique, which has been validated in a laboratory study, allowed multiple mirror and window aperture projections to be created, resulting in the identification and quantification of a key blind spot. The identified blind spot was demonstrated to have the potential to be associated with the scenarios that were identified in the accident data. The project led to the revision of UNECE Regulation 46 that defines mirror coverage in the European Union, with new vehicle registrations in Europe being required to meet the amended standard after June of 2015.
\end{abstract}

Keywords: Digital Human Modelling, trucks, vehicles, blind spot, class V mirror, heavy goods vehicle, vulnerable road user, field of vision, vehicle ergonomics, accident data, cluster analysis

\section{Introduction}

This paper concerns research into the identification and quantification of blind spots in the driver's view from Large Goods Vehicles (LGVs). The current design of LGVs in Europe generally places the driver above the engine of the tractor unit which results in the driver's eye position typically being between 2 and $2.7 \mathrm{~m}$ above the ground plane. Figure 1 shows the eye height of a driver above the ground plane that was captured during the research described in this paper. The height of the driver above the ground combined with the obscuring effect of the vehicle structure makes it difficult for the driver to directly see other vehicles, pedestrians, and cyclists that are in close proximity to the side and front of the tractor unit. 


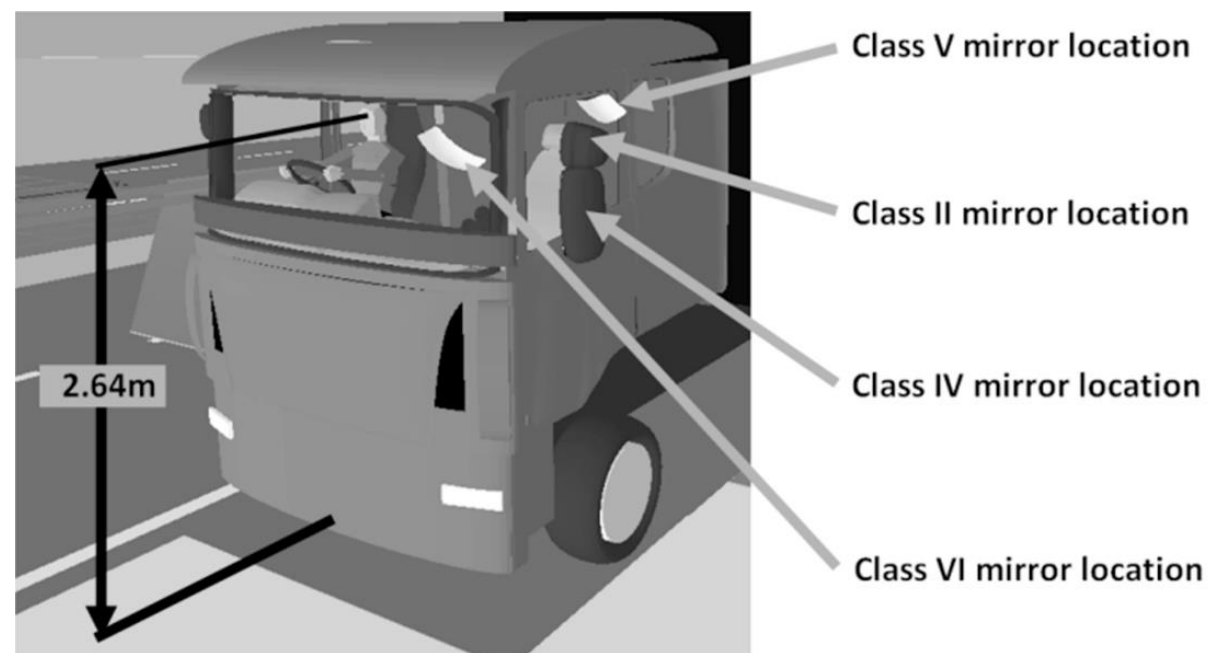

Figure 1. The Category $\mathrm{N}_{3}$ vehicle mirrors and their mounting locations that allow greater visibility of the areas directly adjacent to the vehicle

To account for the limited visibility from the cab, up to six mirrors are mandated for use on Category $\mathrm{N}_{2} \& \mathrm{~N}_{3}$ LGVs that increase the visibility of the area around the cab. Where Category $\mathrm{N}_{2}$ vehicles have a gross vehicle weight between 7.5 and 12 tonnes, and Category $\mathrm{N}_{3}$ vehicles have a gross vehicle weight above 12 tonnes.

Figure 1 shows the location of the mirror classes on an example Category $\mathrm{N}_{3}$ vehicle. The Class II mirror provides a view down the side of the vehicle in same manner as the wing mirrors on passenger cars. The Class IV mirror provides a wide angle view of the area adjacent to the side of the vehicle; the Class $V$ mirror provides a wide angle view of the area directly adjacent to the passenger door, and the Class VI mirror provides a wide angle view of the area directly in front of the vehicle. The minimum field of view afforded to the driver via these mirrors is defined by standard UNECE Regulation 46 (2009). Figure 2 shows the area of the ground plane that is required to be visible to the driver. UNECE Regulation 46 also defines the minimum radius of curvature of these mirrors. For example, the Class V mirror has a minimum radius of curvature of $300 \mathrm{~mm}$ and the Class VI mirror has a minimum radius of curvature of $200 \mathrm{~mm}$.

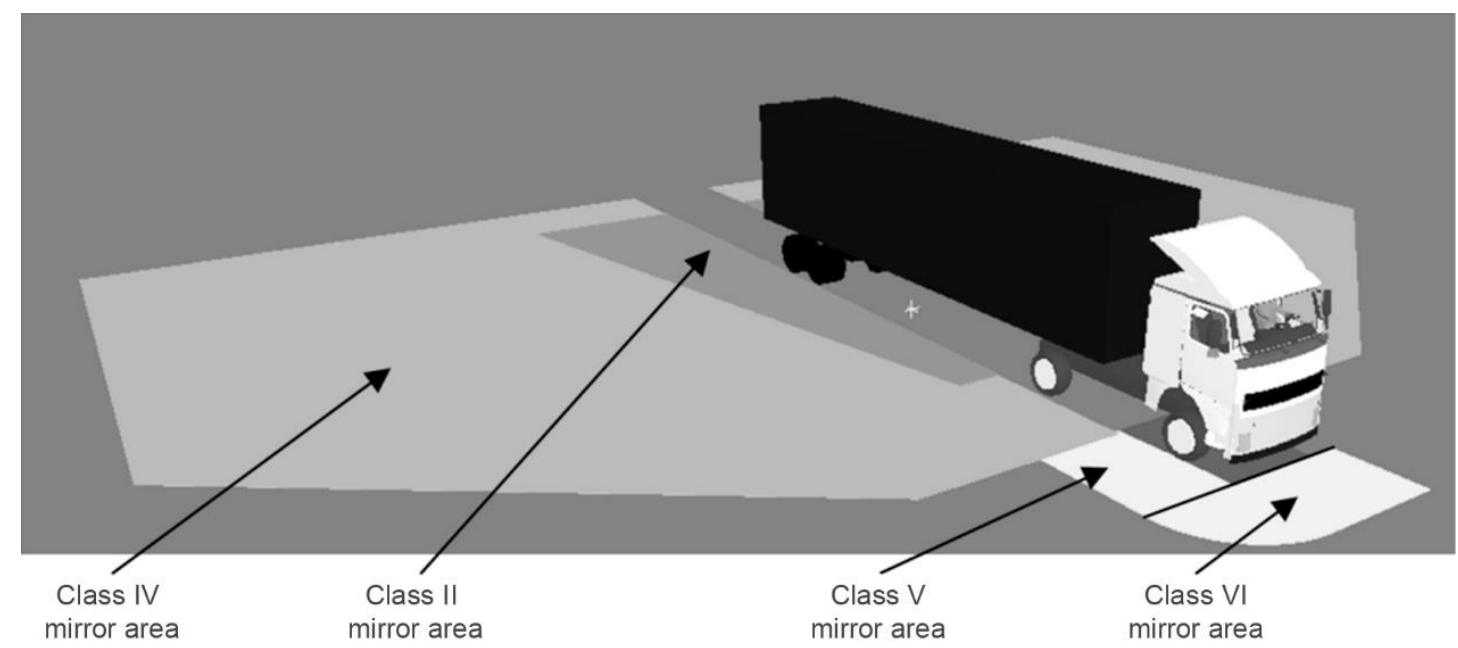

Figure 2. The ground plane areas that are required to be viewed by the driver through the vehicle mirrors as defined in UNECE Regulation $\mathbf{4 6}$ for a left hand drive vehicle 
The design and use of mirrors that are fitted to LGVs has been the subject of a number of research papers. These research activities generally focus upon the difficulty in using the combination of direct vision (through window apertures) and indirect vision (through mirrors) to allow a driver to see the spaces around the vehicle during manoeuvring. Examples include Porter and Stern (1986), where Digital Human Modelling (DHM) was used to simulate mirror specifications with the aim of improving mirror coverage. Tait \& Southall (1999) performed research using real world testing and DHM analysis to make recommendations for the improvements of direct and indirect vision, including the addition of a Class VI mirror (see Figure 1). This involved the analysis of direct vision of vulnerable road users (VRUs) directly in front of the vehicle. Dodd (2009) performed a real world study that modelled the mirror coverage of LGVs by plotting the location of cones around the vehicle placed in positions which were visible to the driver at the edges of each mirror view. Each of these references used two dimensional methods for the presentation of results of mirror coverage by showing the area of the ground plane that is visible to the driver. Two dimensional views are also the method of presentation for information in standards which regulate the areas around a vehicle which should be seen through mirrors by driver, e.g. UNECE Regulation 46.

Despite the on-going research activity and updating of the international standards that define visible areas through mirrors, there have been a number of highly publicised accidents in the UK that involved collisions between LGVs and VRUs such as cyclists and pedestrians, as well as other vehicles. One such accident fostered the creation of the 'See Me Save Me' campaign (SMSE, 2015) which lobbies for the reduction of those killed or seriously injured by collisions with LGVs.

Accidents continue to happen which led the UK government Department for Transport to commission the authors to determine if blind spots exist for the drivers of Category $\mathrm{N}_{2} \& \mathrm{~N}_{3}$ vehicles, and if these blind spots have the potential to contribute to accidents. In order to explore the potential for blind spots a two phase project was defined. The work packages of the research project were designed to define the current understanding of blind spot locations through stakeholder consultation. This involved interviews with a range of UK national bodies, charities and also interviews with the drivers of Category $\mathrm{N}_{2} \& \mathrm{~N}_{3}$ vehicles. In addition to this, accident data were analysed to determine the proportion and severity of accidents that are caused by the drivers of LGVs being unable to see other road users, which resulted in the definition of specific scenarios in which accidents occur between LGVs and VRUs. The results of these initial research activities highlighted the need to explore the potential blind spots in a manner that allowed the interaction between direct vision and indirect vision to be modelled, allowing potential blind spots to be identified. The following paper presents the application of an innovative Digital Human Modelling (DHM) technique which has been designed to model the volume of space that is visible to the driver through multiple windows and mirrors, allowing blind spots to be visualised and quantified in terms of the size of objects that can be obscured from driver's vision.

\section{Methods}

The methods employed in the research project were designed to support the ultimate aim of quantifying the size and location of key blind spots that were associated with accident 
scenarios derived from the UK national STATS-19 and in-depth On-the-Spot (OTS) accident databases (Hill \& Cuerden, 2005). The following sections describe (a) the methods used in the processing of the UK accident databases, (b) the methodology used in the data collection process that was used to derive accurate geometric data for the vehicles analysed and (c) the methods used during the DHM analysis stages.

\subsection{Cluster analysis of UK accident databases to establish key accident scenarios}

In order to examine the prevalence of accidents that occur with Category $\mathrm{N}_{2} \& \mathrm{~N}_{3}$ vehicles where blind spots are a potential contributing factor, the UK STATS-19 accident database from 2008 was interrogated. The method employed to move from accident data to accident scenarios was the data mining technique known as agglomerative or hierarchical ascending cluster analysis (Romesburg, 2004). This progressively groups together the most similar records of a dataset, where the notion of similarity is defined mathematically. In this context each record describes an accident and so the cluster analysis identifies groups of similar accidents. These groups or clusters have (by definition) common characteristics and can be interpreted as constituting accident scenarios. The foremost advantage of applying this method is that the results are objective and reproducible, with an additional benefit that the representativeness of the resultant accident scenarios is clearly defined.

The technical specifications of the algorithm underlying the cluster analysis were selected from a range of standard methods from the literature (Romesburg, 2004; Martinez \& Martinez, 2005; Lenard et al. 2011; Skyving et al. 2009). The computation was carried out in MATLAB (R2009) using the built-in functions pdist, linkage, cophenet, inconsistent and cluster. The algorithm for computing the (dis)similarity or 'distance' between clusters of accidents is specified at three levels:

- At field level, the algorithm was set to compute a distance in the range $0-1$ for any two values of a field, with 0 where the values are the same and 1 where they are not the same.

- At record level, the distance between two accidents was defined as the sum of the distances between the fields-the city block or Manhattan distance.

- At cluster level, the distance between two clusters was defined as the average of the distances between each pair of records in the groups-the average linkage method.

\begin{tabular}{llll}
\hline Field & Type & Value & Description \\
\hline Vehicle movement & Nominal & 1 & Forwards \\
& & 2 & Forwards - left \\
& & 3 & Forwards - right \\
Accident severity & Ordinal & 4 & Backwards \\
& & 0.0 & Slight \\
& & 0.5 & Serious \\
\hline
\end{tabular}

Table 1. The classification system used for vehicle movement and accident severity in the cluster analysis 
For nominal fields, i.e. those that are defined in categories that have no intrinsic order, the distance or dissimilarity between two values is either 0 or 1 , depending whether the characteristic is the same or different for two accidents. Making reference to Table 1, if in two accidents the vehicles are both moving 'forwards-left', the distance is 0 ; if one is moving 'forwards' and the other 'backwards', the distance is 1 . For ordinal fields, i.e. those defined in categories that have an intrinsic order, the range is set to span $0-1$ in equal increments with the distance defined as the absolute value of the difference between the field values, e.g. the distance between a serious accident (assigned 0.5) and a fatal accident (assigned 1.0) is $0.5(|1.0-0.5|)$.

The hierarchical cluster analysis begins with one cluster for each record and iterates through a grouping procedure until ending with one cluster for the whole dataset. No particular set of clusters is right or wrong: each is a valid representation of the data. The question is rather the usefulness of a set of clusters for a particular purpose. Clearly neither extreme-one for each record or one for the whole population-is of interest. For the purpose of identifying typical scenarios it was considered relevant to have a relatively small number of clusters that covers much of the population. Programming code was written to assist in the identification of around six clusters to contain $75-80 \%$ of the population for initial consideration. In conjunction with further code to identify natural gaps between the clusters, the final number (11) was chosen manually after examination of the data. Table 2 shows the outcome of the cluster analysis of 704 accidents associated with goods vehicles, in which a vehicle blind spot was registered as a contributory factor to the accident record. Each column describes the characteristics of a cluster. Cells highlighted in black indicate (a) that the distribution of numbers in the given field is significantly different from the distribution in the total population of 704 goods vehicles (chi-squared test to $99.5 \%$ significance) and (b) that the particular numbers highlighted are overrepresented. The 'representativeness' figures are derived directly from the 'accident severity' category, expressing the latter as row percentages. Cluster 1 can serve to illustrate the interpretation of Table 2. It is the largest cluster, containing 176 of the 704 goods vehicles or $25 \%$ of the population. Almost all of the vehicles (170) in cluster 1 are LGVs over 7.5 tonnes ( $\left.\mathrm{N}_{2} \& \mathrm{~N}_{3}\right)$. Reading down the column, these vehicles are mostly articulated (159) (suggesting that they are $\mathrm{N}_{3}$ category LGVs), were moving forwards and towards the right (154), and made first contact with either the front (50) or right (120) surface. Remarkably, these are all left-hand drive vehicles (176) and all but one collided with a car-sized (or larger) vehicle.

The results from the cluster analysis highlighted the following scenarios for which multiple variables are shown to be significantly different from the distribution in the total population of 704 goods vehicles.

1. Articulated left-hand drive LGVs $\left(\mathrm{N}_{2} \& \mathrm{~N}_{3}\right)$ over 7.5 tonnes changing lane to the right and colliding with cars: $25 \%$ of all casualties, $14 \%$ of serious, $6 \%$ of fatal. (Cluster 1 )

2. LGVs over 7.5 tonnes $\left(\mathrm{N}_{2} \& \mathrm{~N}_{3}\right)$ changing lane to the left and colliding with cars: $24 \%$ of all casualties, $14 \%$ of serious, $6 \%$ of fatal (Cluster 2 ).

3. LGV's below 3.5 tonnes $\left(\mathrm{N}_{2}\right)$ reversing: $16 \%$ of casualties, $29 \%$ of serious and $25 \%$ of fatal (Cluster 3)

4. LGVs ( $\mathrm{N}_{2} \& \mathrm{~N}_{3}$ vehicles) changing lane to the right and colliding with cars: $11 \%$ of all casualties and $2 \%$ of serious (Cluster 4 ). 
5. LGV's ( $\mathrm{N}_{2} \& \mathrm{~N}_{3}$ vehicles), not articulated, moving forwards and colliding will cars, VRUs and Motorcycles: $9 \%$ of casualties, $18 \%$ of serious and $17 \%$ of fatal (Cluster 5 )

6. LGV's ( $\mathrm{N}_{2} \& \mathrm{~N}_{3}$ vehicles), articulated, moving forwards and colliding with cars: $5 \%$ of casualties, $4 \%$ of serious and $25 \%$ of fatal (Cluster 6 )

7. Goods vehicles (all N Classes) turning left and colliding with vulnerable road users: $5 \%$ of all casualties, $10 \%$ of serious, $19 \%$ of fatal (Cluster 7 ).

\begin{tabular}{|c|c|c|c|c|c|c|c|c|c|}
\hline & \multicolumn{8}{|c|}{ Cluster } & \multirow[b]{2}{*}{ Total } \\
\hline & 1 & 2 & 3 & 4 & 5 & 6 & 7 & $8-11$ & \\
\hline \multicolumn{10}{|c|}{ Cluster representativeness (\%) } \\
\hline Slight & 26 & 25 & 15 & 12 & 8 & 5 & 4 & 3 & 100 \\
\hline Serious & 14 & 14 & 29 & 2 & 18 & 4 & 10 & 10 & 100 \\
\hline Fatal & 6 & 6 & 25 & 0 & 19 & 25 & 19 & 0 & 100 \\
\hline Total & 25 & 24 & 16 & 11 & 9 & 5 & 5 & 4 & 100 \\
\hline \multicolumn{10}{|c|}{ Accident severity(Ordinal Data) } \\
\hline Slight & 168 & 161 & 97 & 76 & 54 & 32 & 27 & 22 & 637 \\
\hline Serious & 7 & 7 & 15 & 1 & 9 & 2 & 5 & 5 & 51 \\
\hline Fatal & 1 & 1 & 4 & 0 & 3 & 4 & 3 & 0 & 16 \\
\hline Total & 176 & 169 & 116 & 77 & 66 & 38 & 35 & 27 & 704 \\
\hline \multicolumn{10}{|c|}{ Vehicle type (Ordinal Data) } \\
\hline$L G V<3.5 t$ & 0 & 2 & 91 & 6 & 18 & 0 & 18 & 14 & 149 \\
\hline$L G V<7.5 t$ & 6 & 14 & 8 & 11 & 10 & 5 & 6 & 2 & 62 \\
\hline$L G V>7.5 t$ & 170 & 153 & 17 & 60 & 38 & 33 & 11 & 11 & 493 \\
\hline Total & 176 & 169 & 116 & 77 & 66 & 38 & 35 & 27 & 704 \\
\hline \multicolumn{10}{|c|}{ Articulated vehicle (Nominal data) } \\
\hline Not articulated & 17 & 84 & 116 & 32 & 66 & 0 & 35 & 19 & 369 \\
\hline Articulated & 159 & 85 & 0 & 45 & 0 & 38 & 0 & 8 & 335 \\
\hline Total & 176 & 169 & 116 & 77 & 66 & 38 & 35 & 27 & 704 \\
\hline \multicolumn{10}{|c|}{ Vehicle movement (Nominal data) } \\
\hline Forwards & 18 & 0 & 0 & 0 & 66 & 38 & 0 & 6 & 128 \\
\hline Forwards - left & 4 & 132 & 1 & 6 & 0 & 0 & 35 & 3 & 181 \\
\hline Forwards - right & 154 & 32 & 1 & 71 & 0 & 0 & 0 & 14 & 272 \\
\hline Backwards & 0 & 5 & 114 & 0 & 0 & 0 & 0 & 4 & 123 \\
\hline Total & 176 & 169 & 116 & 77 & 66 & 38 & 35 & 27 & 704 \\
\hline \multicolumn{10}{|c|}{$\begin{array}{l}\text { First point of contact (Nominal } \\
\text { data) }\end{array}$} \\
\hline Front & 50 & 80 & 1 & 0 & 25 & 16 & 2 & 8 & 182 \\
\hline Back & 1 & 0 & 111 & 1 & 5 & 3 & 1 & 7 & 129 \\
\hline Right & 120 & 1 & 3 & 74 & 17 & 9 & 5 & 5 & 234 \\
\hline Left & 5 & 88 & 1 & 2 & 19 & 10 & 27 & 7 & 159 \\
\hline Total & 176 & 169 & 116 & 77 & 66 & 38 & 35 & 27 & 704 \\
\hline \multicolumn{10}{|c|}{ Drive side (Nominal data) } \\
\hline 1 Right & 0 & 169 & 116 & 77 & 66 & 38 & 35 & 19 & 520 \\
\hline 2 Left & 176 & 0 & 0 & 0 & 0 & 0 & 0 & 8 & 184 \\
\hline Total & 176 & 169 & 116 & 77 & 66 & 38 & 35 & 27 & 704 \\
\hline \multicolumn{10}{|c|}{ Collision partner size (Ordinal data) } \\
\hline VRU & 0 & 6 & 82 & 1 & 21 & 10 & 26 & 11 & 157 \\
\hline Motorcycle & 1 & 2 & 16 & 1 & 10 & 1 & 6 & 4 & 41 \\
\hline Car+ & 175 & 161 & 18 & 75 & 35 & 27 & 3 & 12 & 506 \\
\hline Total & 176 & 169 & 116 & 77 & 66 & 38 & 35 & 27 & 704 \\
\hline
\end{tabular}

Table 2. Accident scenarios for goods vehicles 
Of these scenarios cluster 3 relates predominantly to vehicles below 3.5 tonnes, i.e. vans which were considered to be out of scope in terms of identification of blinds spots. The remaining clusters were all of interest and were analysed as part of project, however this paper focuses upon the accidents associated with the passenger side blind spot. This is associated with vehicle making forwards-left (right hand drive vehicles) and forwards-right (left hand drive vehicles) movements, represented by clusters 1, 2, 4 and 7.

In order to explore these scenarios in further detail, the UK On-the-Spot accident database (Hill \& Cuerden, 2005; Cuerden et al. 2008) was used to identify specific accidents that relate to the identified scenarios.

\subsection{The use of Digital Human Modelling Software to identify blind spots in driver's vision}

As discussed in the introduction previous research has utilised two dimensional analysis techniques in the identification and presentation of mirror and blind spot modelling. In defining a methodology for the analysis of blind spots it was considered important by the authors to allow the visualisation of the volume of space that is visible to the driver through mirrors and windows in a three dimensional manner to allow an understanding of blind spot location and size. In order to facilitate this the existing features of the SAMMIE CAD DHM system (Porter et al. 2004) were modified to allow the projection of multiple mirrors and multiple window apertures simultaneously. The SAMMIE DHM system is developed by the project research team. The technique that was developed for the projection of mirrors and windows is described in Marshall et al. (2013), which includes detail on the validation of the technique using a laboratory based study.

The value of this three dimensional approach to blind spot modelling can be seen in Figure 3 . The situation being modelled in Figure 3 is the projection of the Class $V$ mirror which looks down the side of the drivers cab. The rectangular shape on the floor next to the cab highlights the area of the floor that should be visible to the driver as defined by the standard UNECE Regulation 46. A pedestrian (50th\%ile UK female with a stature of $1634 \mathrm{~mm}$ ) has been placed within the rectangular area. The plan view of the situation being modelled in Figure 3 (left image) shows that it could be presumed that the pedestrian is visible to the driver, as the human model is within rectangular area. However, the three dimensional view (Figure 3, right image) illustrates that only the feet and part of the lower leg intersect with the mirror projection, meaning that only these would actually be visible to the driver in the mirror. Part of the pedestrian would be seen in the bottom right hand corner of the mirror from the driver's view, with a small area of the mirror containing the view of the foot and leg, as indicated by the proportion of the mirror volume that is intersecting with the pedestrian. Therefore the use of three dimensional projections to explore the visibility of VRUs around the cab of LGVs provides a more accurate analysis method when compared to using two dimensional plan view representations of scenarios, as the complex three dimensional structure of the mirror projections cannot be represented in two dimensions. 


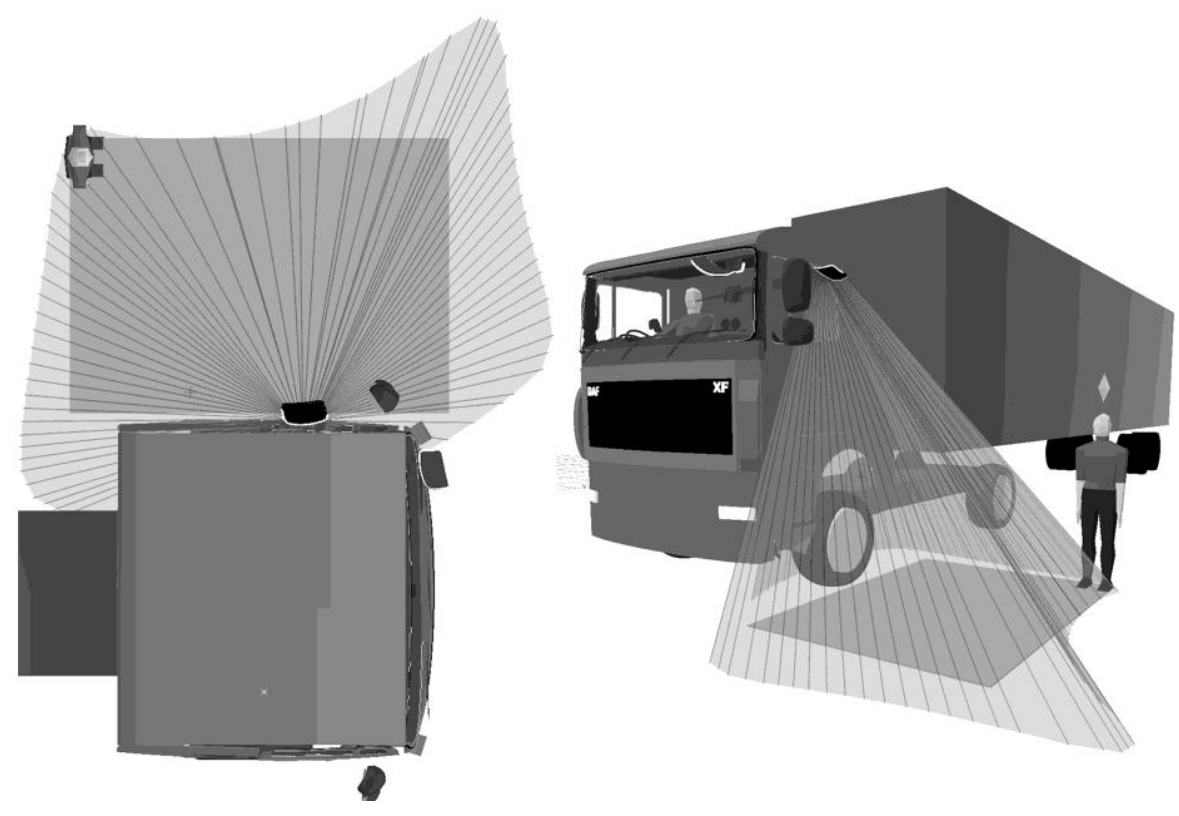

Figure 3. Illustrating an example of the presentation of the volume of space that is visible to the driver through the Class $\mathbf{V}$ mirror using two dimensional and three dimensional methods

The simultaneous projection of all mirrors and all windows allows blind spots in the vision of the driver to be explored through the mechanism of iteratively positioning models that simulate VRUs and vehicles around the cab to determine if they can be obscured from the driver. Figure 4 shows the result of projecting all mirrors, all windows and the combination of all windows and mirrors, allowing the interaction between these projections, and where blind spots lie, to be visualised by the user of the software.

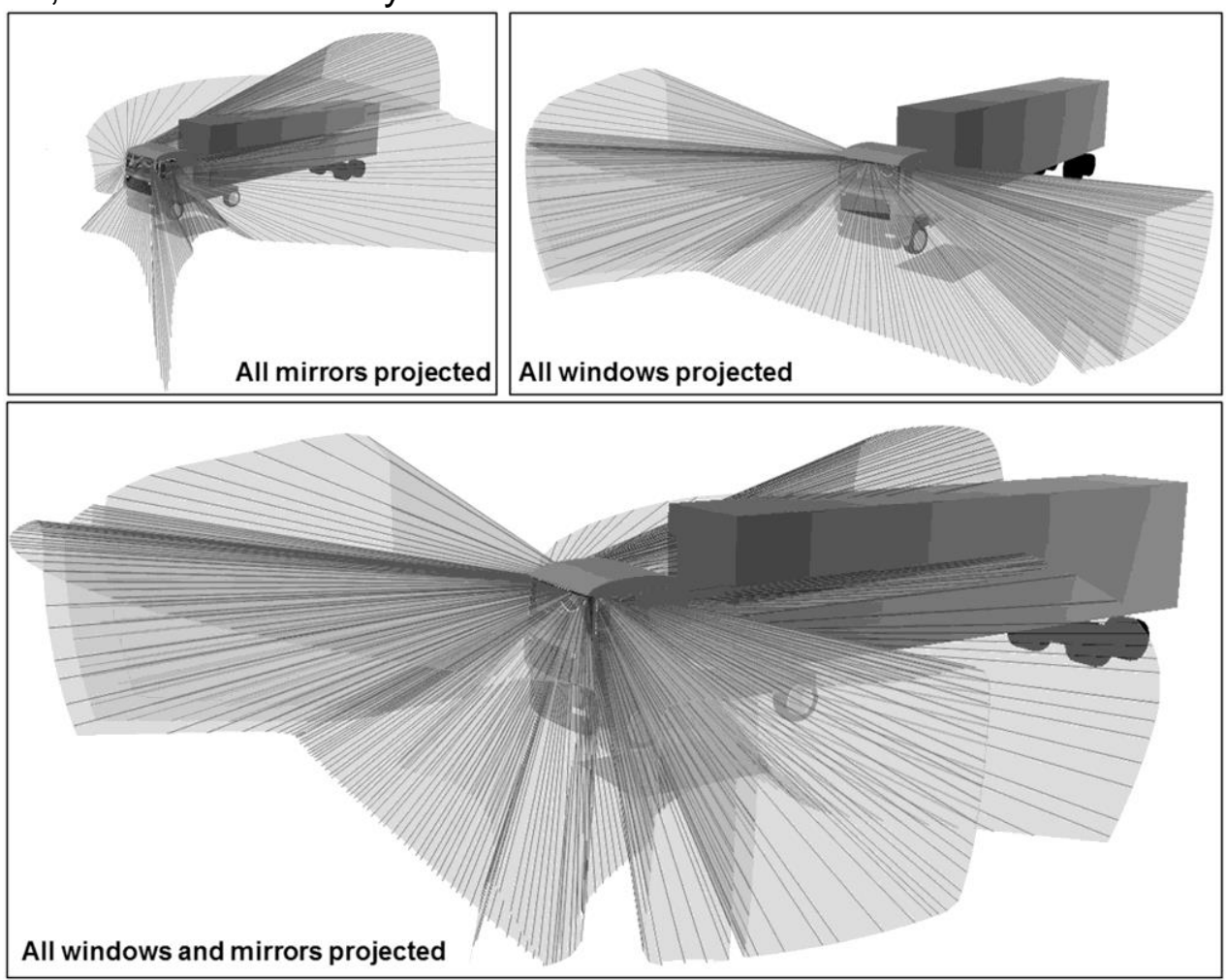

Figure 4 illustrates the projection technique being used to project all mirrors (top left image), all windows (top right image) and the combination of both mirrors and windows (bottom image) 


\subsection{Simulating the variability in driver posture and occular points}

The SAMMIE DHM projection technique relies upon the location of the eye point for each human that is simulated as this is the origin of the projection method. The eye position variability within the vehicle of the driver population is defined by a number of factors including the anthropometry of the population, the available seat and steering wheel adjustability in vehicles, and the driving posture that results from the available adjustability.

The process of vehicle design and assessment is supported by a number of International Standards Organisation (ISO), Society of Automotive Engineers (SAE) and European Standards. The variability of eye location within the vehicle due to driver size variability is specifically addressed by SAE J941 (1997) through the use of Eyellipse contours (a contraction of the words eye and ellipse) which illustrate the eye point variability in different vehicle types. The Eyellipse data available for LGVs in SAE J941 is outdated in that it does not take into account truck designs with height adjustable seats and is therefore not applicable to modern vehicle designs (Reed, 2005). There was therefore a requirement to explore eye point variability using other sources of information. The approach taken involved the capture of driving postures to support the creation of postures in the DHM system. Twenty drivers with a stature range of 4th\%ile UK male (Adultdata, 1998) with a stature of $1635 \mathrm{~mm}$ to $99 \mathrm{th} \%$ ile stature UK male with a stature of $1912 \mathrm{~mm}$ were photographed in their vehicles with examples shown in Figure 5. The largest and smallest drivers were selected to provide the widest range of eye position. A series of dimensions were captured from the drivers and the vehicles that they drive to allow driving postures to be recreated. Table 3 shows the measures taken from the drivers and the equipment used.
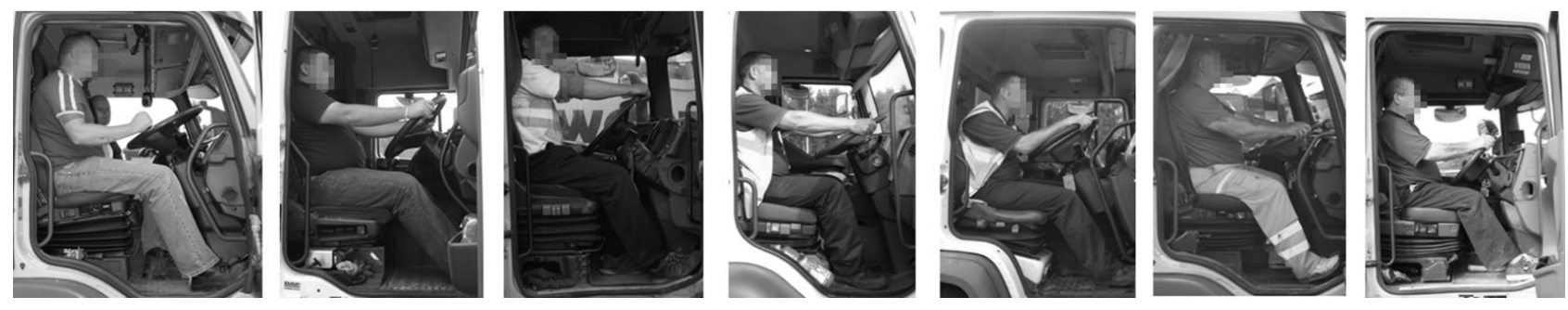

Figure 5 . The variety of driver postures exhibited by drivers with a 4th\%ile to 99th\%ile stature range using UK anthropometric data (ADULTDATA 1998) 


\begin{tabular}{ll}
\hline Measurement & Measuring equipment \\
\hline Driver Anthropometry & \\
\hline Stature & Stadiometer \\
Sitting Height & Sitting height table \\
Buttock knee length & Sitting height table and anthropometer \\
Knee height & Anthropometer \\
Arm Length & Tape measure \\
Sitting shoulder height & Sitting height table and anthropometer \\
Hand length & Tape measure \\
Shoulder breadth & Anthropometer \\
Driver's eye position (height and lateral distance) from the & Anthropometer, sprit level and tape \\
Accelerator heal point (AHP) & measure from the AHP \\
\hline Driving posture joint angles & \\
\hline Ankle angle with foot on the undepressed accelerator & Goniometer \\
Knee angle & Goniometer \\
Thigh truck angle & Goniometer \\
upper arm angle to the vertical & Goniometer \\
Elbow angle & Goniometer \\
Neck angle & Goniometer \\
\hline
\end{tabular}

Table 3. The measures that were taken during the capture of driver posture

Driving posture joint angles were captured using goniometry with methods described by Rothstein (1983). The research team were all qualified ergonomists who had been trained in the use of the 'Harpenden' stadiometer, sitting height table and anthropometer (Holtain, 2015). For each measure three dimensions were taken and the mean of these dimensions were used (Low, 1976). The combination of driver anthropometry and joint angle data allowed the postures captured from the drivers' to be recreated in the DHM system. This process involved the analysis of the seat height adjustability and steering wheel adjustability of each vehicle from which the drivers' postures were gathered, to ensure that the vehicles which were being modelled in the DHM system could also achieve these seat and steering wheel adjustability measures. The resultant eye point defined by the posture in the DHM system was matched to the drivers' eye position data that was captured as described in Table 3. This provided three candidate eye positions for use with the projection technique. These were then validated by comparison to the Eyellipse data which does account for seat height variability using methods defined by Reed (2005). These data were produced by Reed to provide a model for the definition of Eyellipse data in the absence of an up to date SAE standard. The technique defined requires the utilisation of dimensions that are captured from the vehicle that relate to the adjustability of the seat and steering wheel with reference to the standardised accelerator-heel point (AHP) as defined in SAE standard J4002, (2005). With these data it is possible to define an Eyelipse which is customised for each vehicle. 


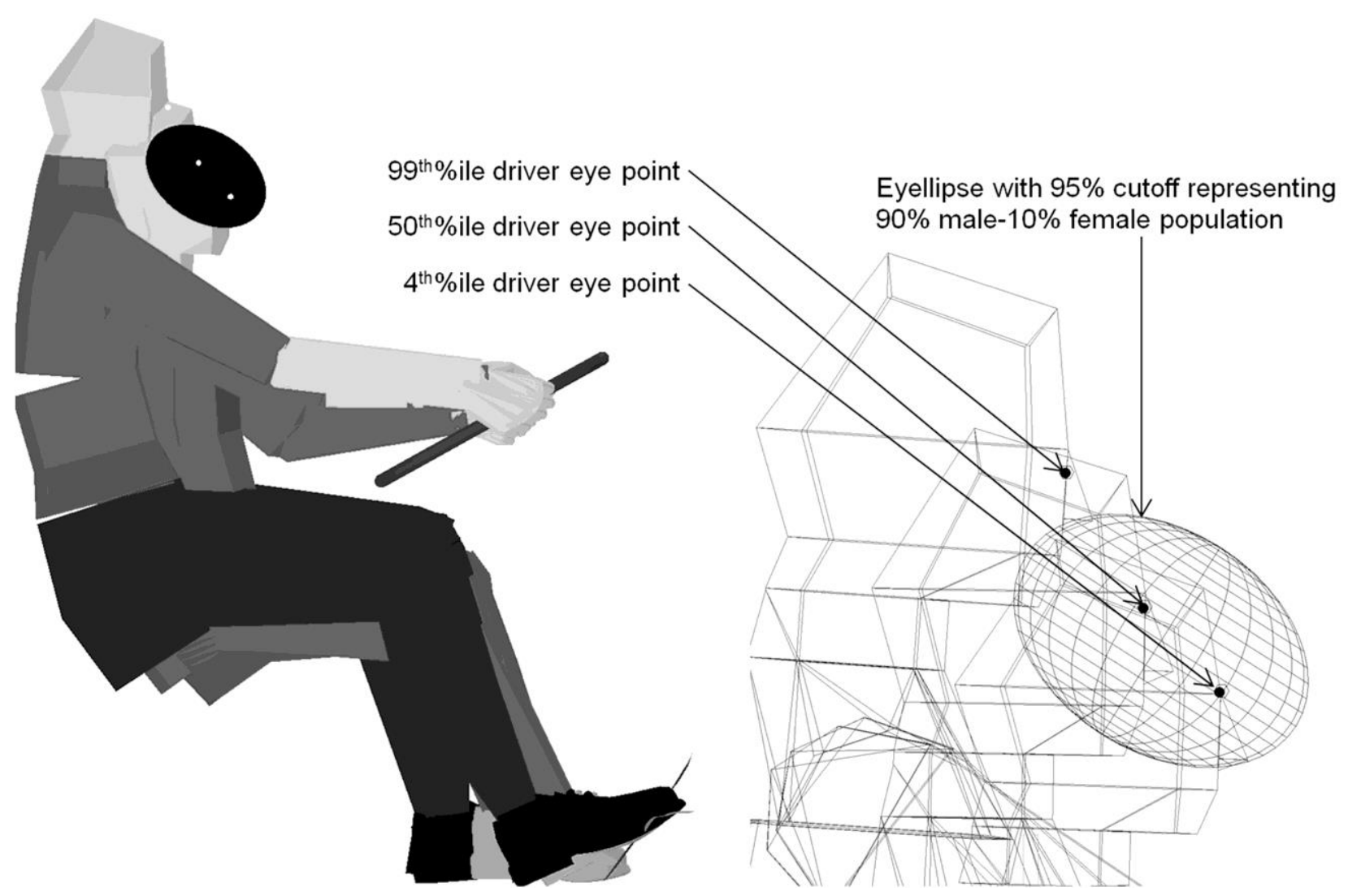

Figure 6. illustrates a comparison between the three eye points that were defined by capturing driver postures, and the Eyellipse generated using methods described in Reed (2005)

Figure 6 shows a comparison between the Eyellipse generated for the DAF XF LGV, and the eye points that were generated by taking measures from three drivers. The Eyellipse generated represents $95 \%$ accommodation limits of a population that contains $90 \%$ male and $10 \%$ female drivers. The distribution of eye points for male and female drivers within the Eyellipse show that female drivers exhibit eye points biased to the bottom right of the Eyellipse shown in Figure 6, and the male drivers exhibit eye point locations biased to the top left as shown in Reed (2005). The three eye points defined by the driver postures captured in the study lie in expected locations when compared to the Eyellipse data, i.e. the 99th\%ile eye point is outside of the Eyellipse, which covers only $95 \%$ of the population, and is above the Eyellipse. The 4th\%ile driver's eye point is within the Eyellipse and located in the bottom half of the Eyellipse, as would be expected for a smaller male driver. The 50th\%ile driver's eye point is within the Eyellipse and between the location of the centroids for the male and female data (see Figure 5, in Reed, 2005). Therefore the Eyellipse data validated the locations of the eye points as being not only possible, but in generally expected locations. Therefore the method defined has produced three eye points which allow an examination of the variability of eye location due to driver size in a manner which can be consistently applied to each vehicle that is tested using the projection technique. 


\subsection{The vehicle and digitization process}

The selection of the vehicles that were analysed in the research was performed using UK sales data provided by The Society of Motor Manufacturers and Traders (SMMT, 2015). This allowed the UK top three selling Category $\mathrm{N}_{2} \& \mathrm{~N}_{3}$ vehicles to be identified. The DAF 45, Iveco EuroCargo, and Renault Midlum (all right hand drive) were selected in the $\mathrm{N}_{2}$ category and the DAF XF 105, Volvo 480 and SCANIA R420 were selected for the $\mathrm{N}_{3}$ category. The Volvo vehicle was left hand drive to allow an analysis of the situation for vehicles driving on UK roads (right hand drive road layout) that originate from mainland Europe (left hand drive road layout) as defined by Cluster 1 (see Table 2). The DAF and SCANIA vehicles were right hand drive. A review of the configurations available of the top ten selling vehicles was performed to ensure that there were no vehicle designs which vary from the configurations that were selected based upon sales data. Four of the top 10 Category $\mathrm{N}_{3}$ vehicles were low entry cabs which were not of interest. Figure 7 shows the top six selling category $\mathrm{N}_{3}$ vehicles that matched the category of interest in the research, and how they share the same basic layout with the cab above the engine and the use of the mandatory mirror set defined by UNECE Regulation 46. Each of the selected vehicles were sourced and digitized by the project partners at MIRA (MIRA, 2015). The scanning process was performed in three dimensions using the FARO ARM data capture system (FARO, 2015). Table 4 shows the dimensions captured from each vehicle. These data were then surfaced using the parametric Computer Aided Design system, Pro Engineer (PTC, 2015) and then imported into the SAMMIE DHM system for analysis.

\begin{tabular}{ll}
\hline Vehicle data to allow models to be built & \\
\hline Seat fore adjust with reference to the Accelerator Heel point (AHP) & Anthropometer \\
Seat Height adjust with reference to the cab floor & Anthropometer \\
Seat base angle & Inclinometer \\
Seat back angle & Inclinometer \\
Steering wheel height (Lowest point to the cab floor) & Anthropometer \\
Steering wheel angle & Inclinometer \\
Seating Reference Point (SgRP or R-point) in lowest rearmost seat adjustment position & SAE H-point manikin \\
Interior and exterior data for the geometry of the vehicle and mirrors & FARO ARM \\
Class II, IV, V and VI mirrors shape and radius of curvature & FARO ARM \\
Window aperture contours & FARO ARM \\
Exterior panels & FARO ARM \\
Mirror mounting structures & FARO ARM \\
Interior panels & FARO ARM \\
Seat cushions in extreme adjustment positions (fully up, fully down, fully forward, fully rearwards) & FARO ARM \\
Steering wheel locations (fully up, fully down, fully forward, fully rearwards) & FARO ARM \\
\hline
\end{tabular}

Table 4. The data captured during the digitization of the vehicles that were selected for analysis 

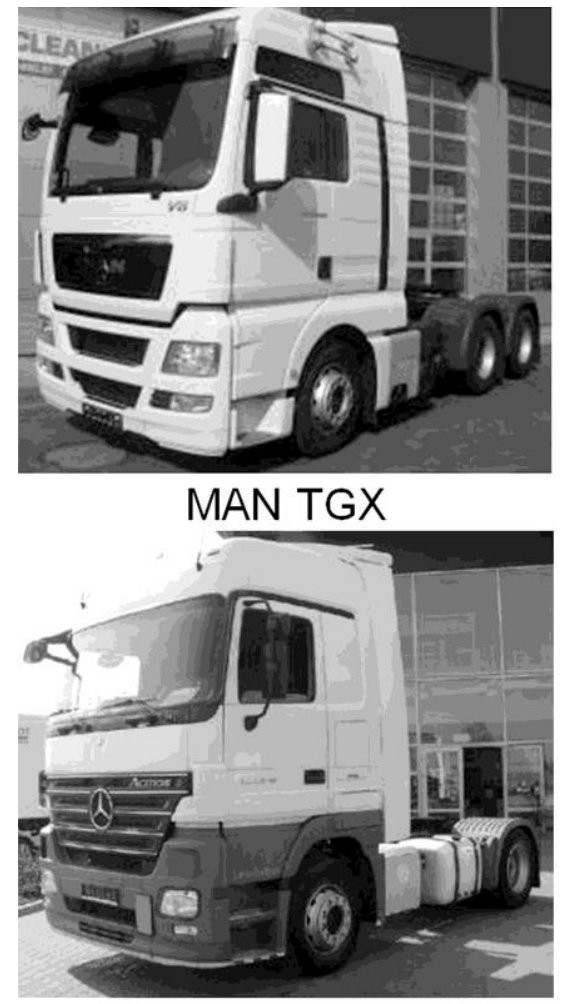

Mercedes Actros

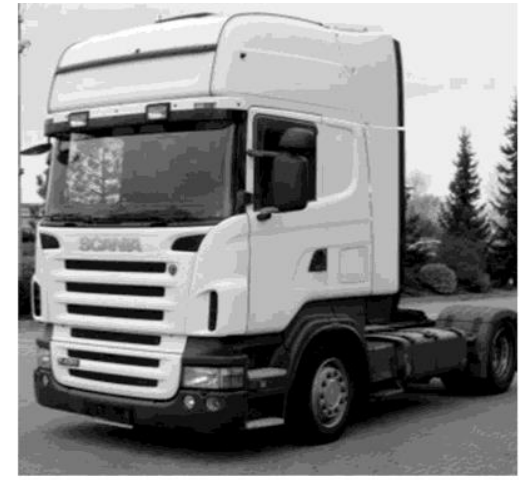

SCANIA R

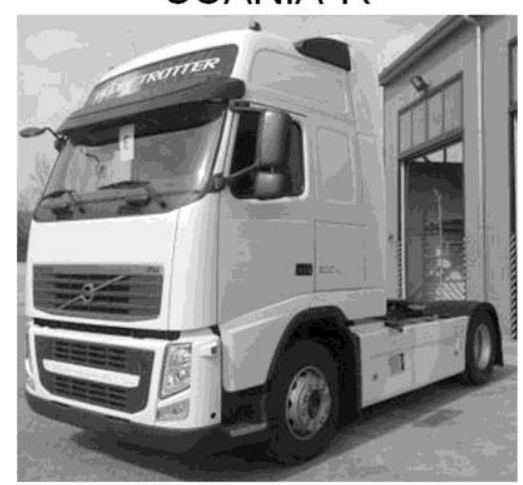

Volvo $\mathrm{FH}$
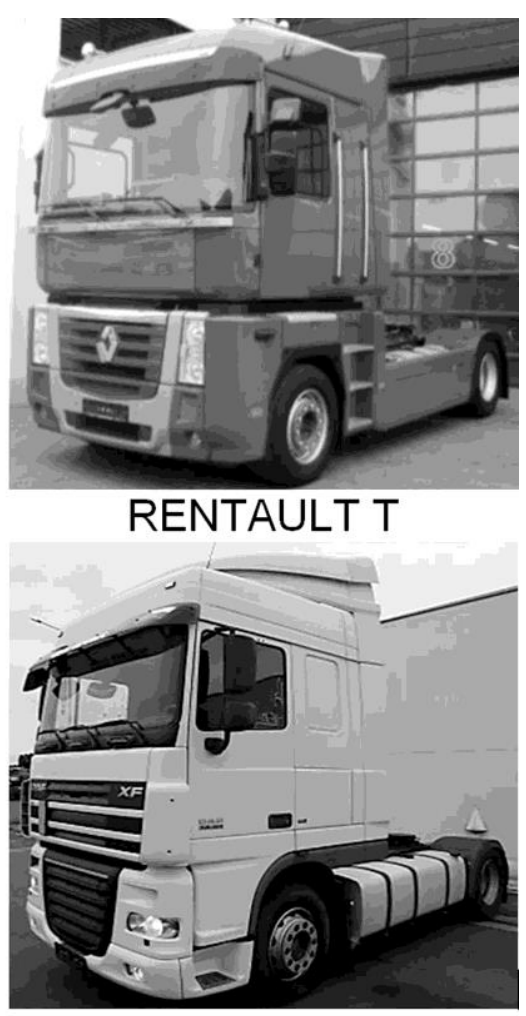

DAF XF

Figure 7. Comparing the configurations of the UK's top six selling Category $\mathrm{N}_{3}$ tractor units

\subsection{DHM system methodology}

Each of six vehicles were setup in the DHM system to allow appropriate adjustment of the mirrors. The Class II and Class IV mirrors were adjustable within the mirror mounting structures on a ball joint, the centre of rotation of which was identified using the scanned data of the mirrors in four extreme adjusted positions. The rotation points of the Class $\mathrm{V}$ and Class VI mirrors that allow adjustment were identified from the scanned vehicle data. All mirrors were then constrained to allow rotation through their available range of motion in the DHM system using the modifications function, which allows angular constraints to be applied to the motion of objects. Digital human models were created and postured as per the description in section 2.3. Using the projection technique shown in Figure 3, and the standard UNECE Regulation 46 ground plane areas shown in Figure 2, the virtual mirrors were adjusted to ensure that the standards were being met for each of the driver sizes. The decision was taken to adjust the mirrors to meet the standards as it was considered important to determine if blind spots exist when mirrors are correctly adjusted.

The identified blind spots were then tested by modelling the identified scenarios. Scenarios 1,2 and 4 were associated with change lane manoeuvres and so a three lane highway was modelled in the DHM system with a standard lane width of $3.5 \mathrm{~m}$. A Category $\mathrm{M}_{1}$ vehicle (passenger car: width of $1.9 \mathrm{~m}$, length of $3.6 \mathrm{~m}$ and height of $1.45 \mathrm{~m}$ ) was used as a visual target for the analysis of 'side swipe' scenarios. For all tests the visual target vehicle was placed forwards of the volume of space visible in the Class IV mirror, with the side of the car closest to the LGV being $2 \mathrm{~m}$ from the side of the LGV, and therefore outside of the zone of coverage of the Class V mirror, it was then determined if the car could be seen through the passenger window. Scenario 4 , involved Category $\mathrm{N}_{3}$ vehicles turning left at 
junctions in the UK and colliding with cyclists. The number of variables associated with this scenario (junction size, orientation, and positioning of the cyclist and the Category $\mathrm{N}_{3}$ vehicle) provided numerous combinations and potential outcomes. In order to provide structure for the analysis, a specific OTS case was identified that met the conditions of the scenario. The OTS case data includes detailed location information, allowing an accurate model of the junction to be defined. The visual target for the analysis was a $50^{\text {tho }} \%$ ile stature UK female adopting a cycling posture, whilst stationary at the junction and adjacent to a LGV that is about to make a left hand turn.

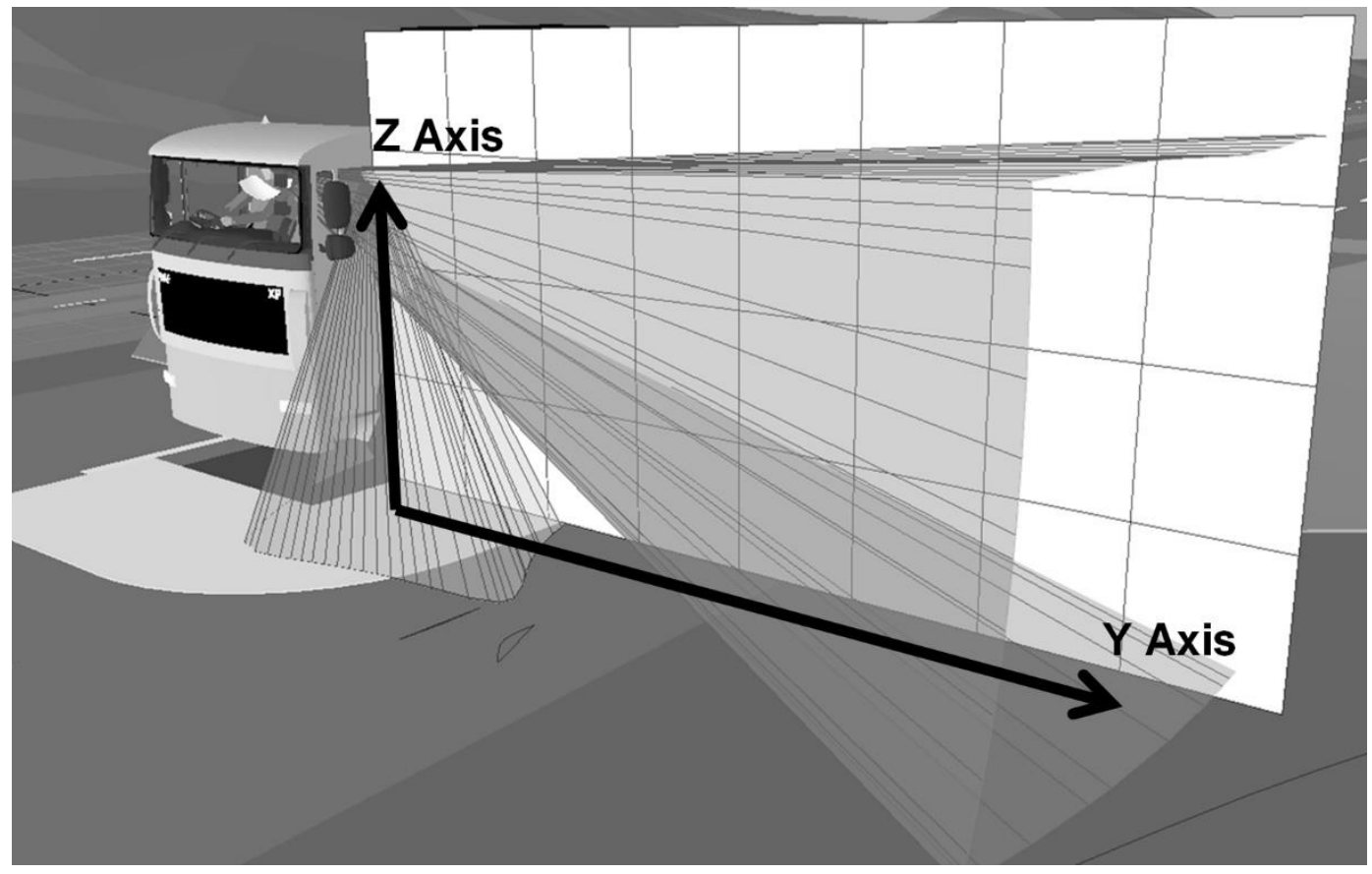

Figure 8. The vertical plane passing through the driver's ocular points which was used to take a sectional view of the Class V mirror and window aperture projections

The projection technique that has been used in the research produces complex interactions between the mirror and window aperture projections that allow blind spots to be visualised. These blind spots are best conceptualised through dynamic manipulation of the software operator's view of the screen based output. In order to provide a clear visualisation of the identified blind spots a section of the combined mirror and window aperture projections was taken through the vertical plane passing through the driver's ocular points i.e. the Y-Z plane using the coordinate system defined in SAE J1100 (1995) as shown in Figure 8.

\section{Results}

The results of the volumetric analysis highlighted a key blind spot that was consistent across all six of the Category $\mathrm{N}_{2} \& \mathrm{~N}_{3}$ vehicles that were analysed, although the size of this blind spot did vary. This blind spot exists between the volume of space that is visible to the driver through direct vision and the volumes of space that are visible through the Class II, IV and V mirrors. The identified blind spot was then tested in terms of the scenarios that were defined in the accident data analysis discussed in section 2.1. 


\subsection{Comparison of the size of the identified blind spot for the vehicle sample}

The sectional view of the volumetric projections for the passenger window and Class $\mathrm{V}$ mirror are shown in Figure 9 and Figure 10 for the category $\mathrm{N}_{2}$ and $\mathrm{N}_{3}$ vehicles respectively. The visual targets shown in Figure 9 and Figure 10 are three 50th\%ile stature UK female (Adultdata, 1998) cyclists line abreast (width of the three cyclists $=1.77 \mathrm{~m}$, height $=1.5 \mathrm{~m}$ ) and a category $\mathrm{M}_{1}$ passenger vehicle (width of the vehicle $=1.9 \mathrm{~m}$, height $=$ $1.43 \mathrm{~m}$ ). The 99th\%ile stature LGV driver was selected for this test to illustrate the best case i.e. the higher eye point of the 99th\%ile male driver generates the smallest blind spot. Therefore the size of the identified blind spot would be larger for smaller drivers, as their lower eye position in the cab would result in less of the exterior of the cab being visible through the window apertures.

The size of blind spot varies between vehicles, and most notably between categories. The Category $\mathrm{N}_{2}$ vehicles shown in Figure 9 have lower cabs than the Category $\mathrm{N}_{3}$ vehicles and so the size of the identified blind spot is smaller in these vehicles. Figure 9 shows that the visual targets of a category $M_{1}$ vehicle and 50th\%ile stature UK female cyclists are only partially obscured from the driver's vision, with the head and shoulders of all cyclists, and the side windows and roof of the car being visible to the driver through the window for all Category $\mathrm{N}_{2}$ vehicles. Figure 10 shows the results for the Category $\mathrm{N}_{3}$ vehicles, and that for the DAF XF 105 and the Volvo 480, the visual targets are completely obscured from the LGV driver. The Scania R420 allows the head of the furthest cyclist from the LGV to be seen, as well as part of the roof of the car. To allow further quantification of the blind spot a measure was taken of the height of an object that can be obscured $2 \mathrm{~m}$ from the passenger door (i.e. at the edge of the Class $V$ mirror coverage) for the 99th\%ile driver eye point. This data is shown in table 5 and shows a range of $800 \mathrm{~mm}$ to $1800 \mathrm{~mm}$ for all tested vehicles.

\begin{tabular}{|c|c|c|c|c|c|c|}
\hline & $\begin{array}{l}\text { Category } \\
\mathrm{N}_{2} \text { DAF } 45\end{array}$ & $\begin{array}{l}\text { Category } \mathrm{N}_{2} \\
\text { IVECO } \\
\text { EUROCARGO }\end{array}$ & $\begin{array}{l}\text { Category } \mathrm{N}_{2} \\
\text { Renault } \\
\text { MIDLUM } \\
\end{array}$ & $\begin{array}{l}\text { Category } \\
N_{3} \text { SCANIA } \\
\text { R420 } \\
\end{array}$ & $\begin{array}{l}\text { Category } \\
N_{3} \text { DAF XF } \\
105 \\
\end{array}$ & $\begin{array}{l}\text { Category } \\
\mathrm{N}_{3} \text { VOLVO } \\
480 \\
\end{array}$ \\
\hline $\begin{array}{l}\text { The height of the } \\
\text { lowest point of the } \\
\text { Class V mirror above } \\
\text { the ground plane }\end{array}$ & $2183 \mathrm{~mm}$ & $2231 \mathrm{~mm}$ & $2150 \mathrm{~mm}$ & $2669 \mathrm{~mm}$ & $2717 \mathrm{~mm}$ & $2747 \mathrm{~mm}$ \\
\hline $\begin{array}{l}\text { Obscured object } \\
\text { height } 2 \mathrm{~m} \text { from the } \\
\text { passenger door for } \\
99^{\text {thoile stature }} \\
\text { driver eye point }\end{array}$ & $900 \mathrm{~mm}$ & $1180 \mathrm{~mm}$ & $800 \mathrm{~mm}$ & $1610 \mathrm{~mm}$ & $1770 \mathrm{~mm}$ & $1800 \mathrm{~m}$ \\
\hline
\end{tabular}

Table 5. The height of the lowest point of the Class $\mathrm{V}$ mirror above the ground plane and the height of an object that can be obscured $2 \mathrm{~m}$ from the passenger door 


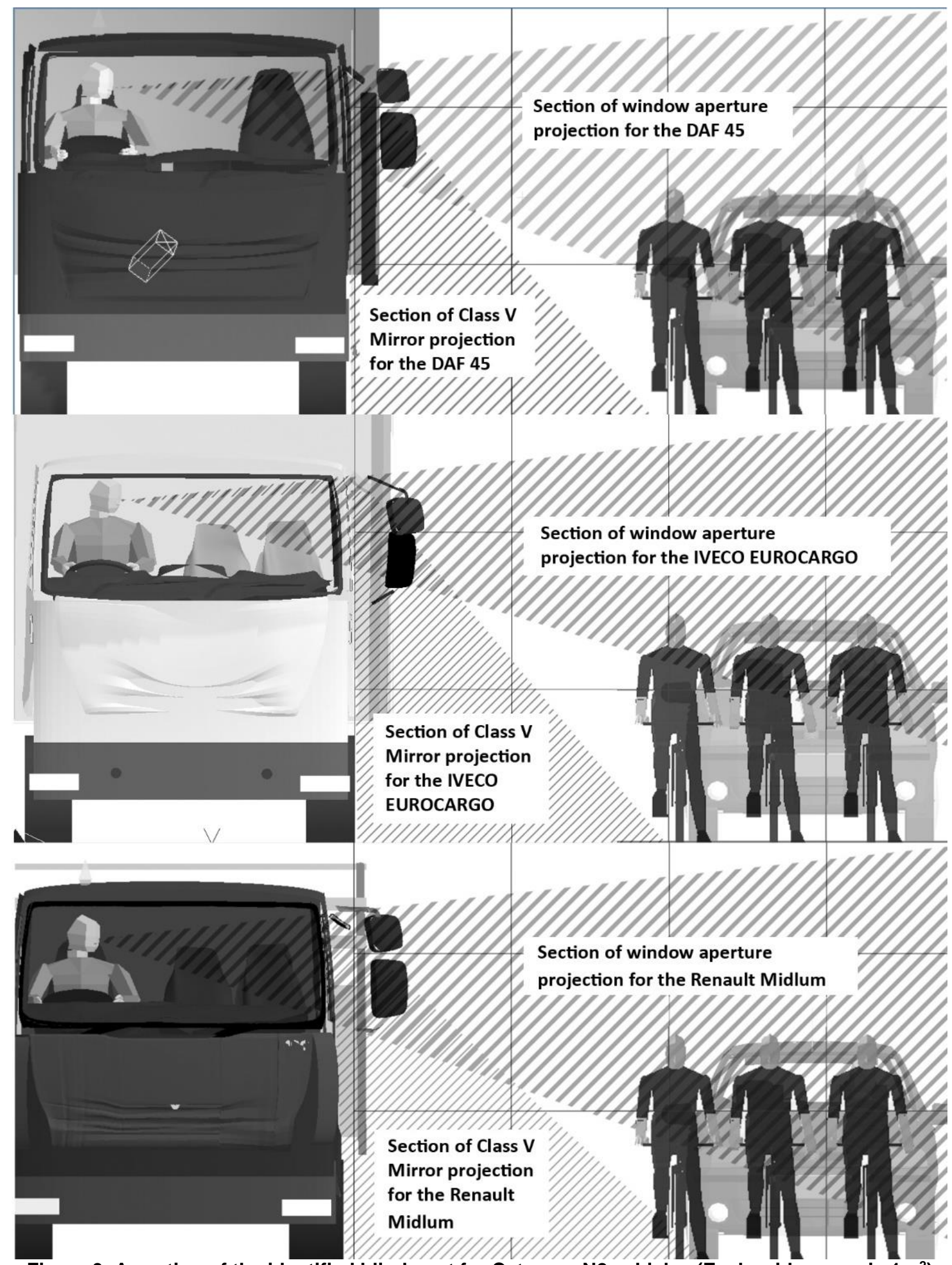

Figure 9. A section of the identified blind spot for Category N2 vehicles (Each grid square is $1 \mathrm{~m}^{2}$ ) 


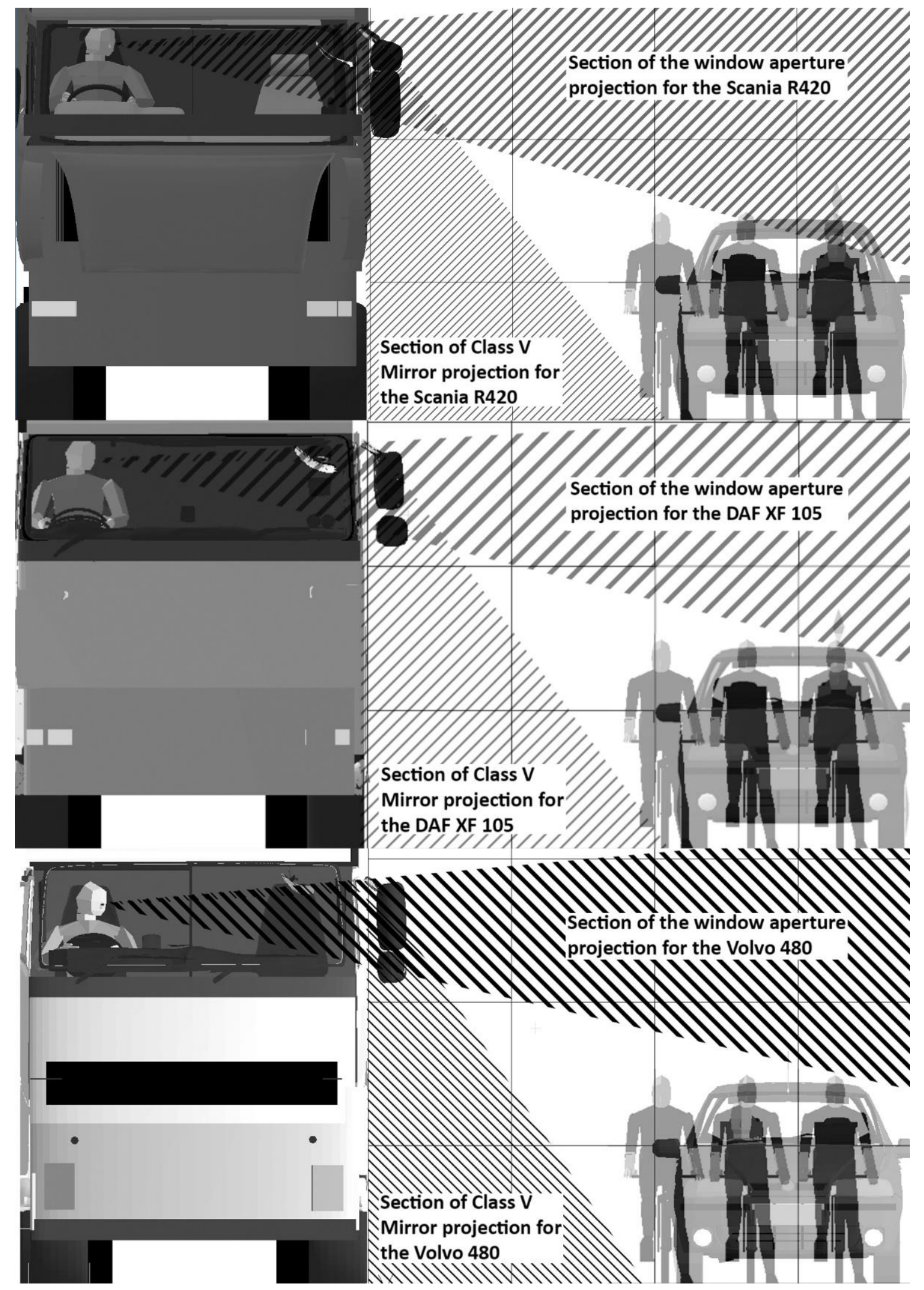

Figure 10. A section of the identified blind spot for Category N3 vehicles (Each grid square is $1 \mathrm{~m}^{2}$ ) 


\subsection{Results from the analysis of side swipe scenarios}

The analysis of the 'side swipe' accidents (scenarios 1,2 and 4) highlighted in the accident data showed varying potential for the obscuration of the category $M_{1}$ vehicle between the three Category $\mathrm{N}_{3}$ LGVs that were tested. For the Volvo 480, locations were identified where the whole target vehicle could be obscured from the LGV driver's direct and indirect vision. For the DAF XF, a location was identified where only a small portion of the side of the target vehicle was visible in the Class V mirror. For the SCANIA R420 a portion of the front quarter of the target vehicle was visible in the Class V mirror, and a portion of the roof was visible through direct vision. See Figure 11.

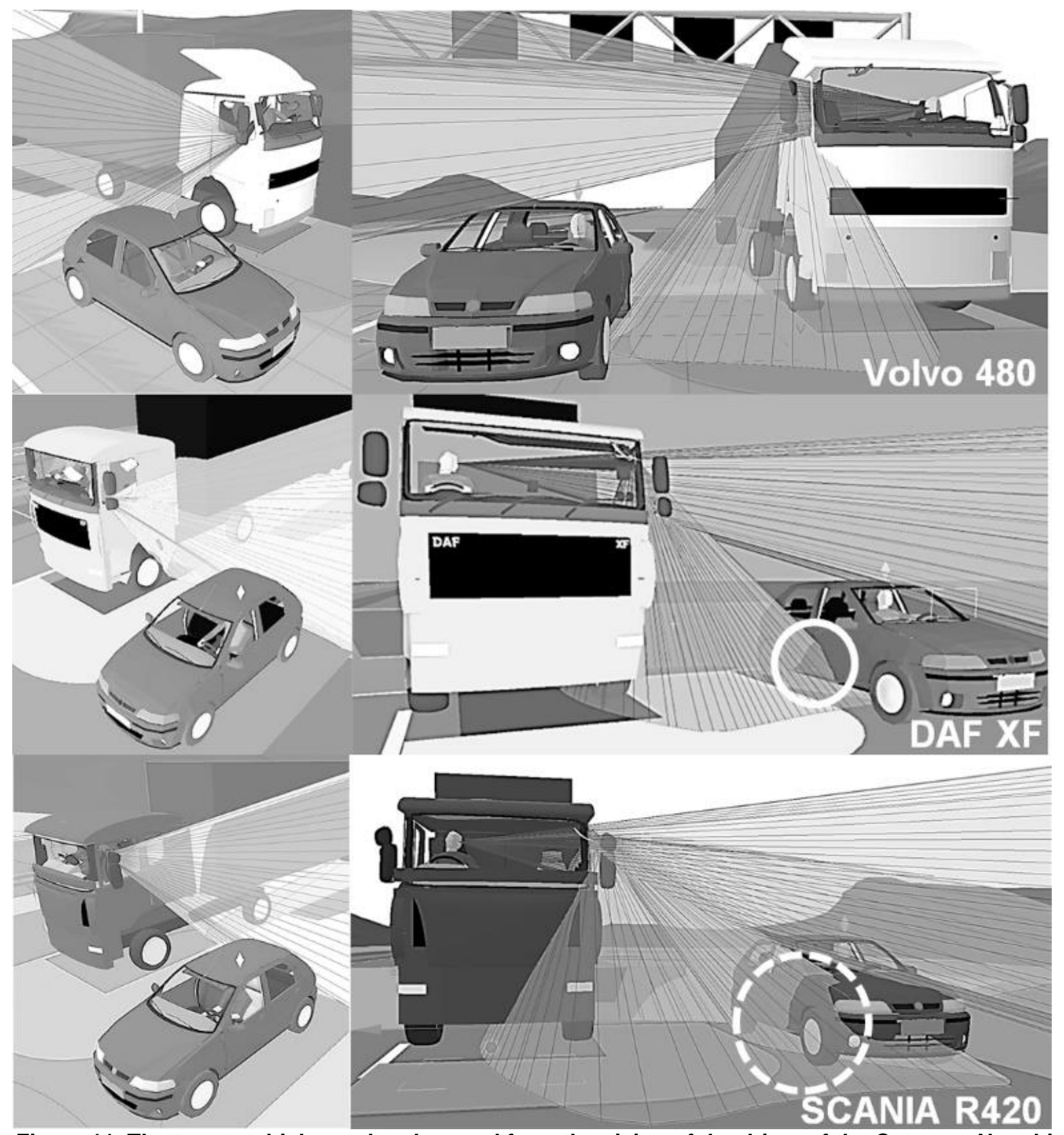

Figure 11. The target vehicle can be obscured from the vision of the driver of the Category $\mathrm{N}_{3}$ vehicle 


\subsection{Results from the analysis of scenario 4}

The analysis of the specific OTS scenario that resulted in the injury of a cyclist was based upon the premise that the driver should not be aware of the cyclist being in a location that is to the left of the Category $\mathrm{N}_{3}$ vehicle before pulling away and starting the left hand turn. Each Category $\mathrm{N}_{3}$ vehicle was placed in the far right section of the lane to better allow the left hand turn to be completed based upon consultation with LGV drivers. It was then determined if it is possible for the cyclist to be completely obscured from the driver's vision for all of the test vehicles by changing the position of the cyclist in relation to the LGV. Figure 12 shows the junction that was modelled from the OTS data (top image) and the complete obscuration of the cyclist from the LGV driver for all three tested vehicles. The cyclist was obscured from the driver of the Volvo 480 (left hand drive) by positioning the cyclist $400 \mathrm{~mm}$ from the driver's door as shown in Figure 12 (bottom left hand image). The cyclist was obscured from the drivers of the Scania R420, and the DAF XF 105 by positioning the cyclist forward of the region visible in the Class IV mirror and $2 \mathrm{~m}$ (outside of the Class V mirror coverage) from the side of the vehicle. The results show that it is possible for a cyclist to be completely obscured from the drivers of both left hand drive and right hand drive LGVs vehicles in the defined scenario.

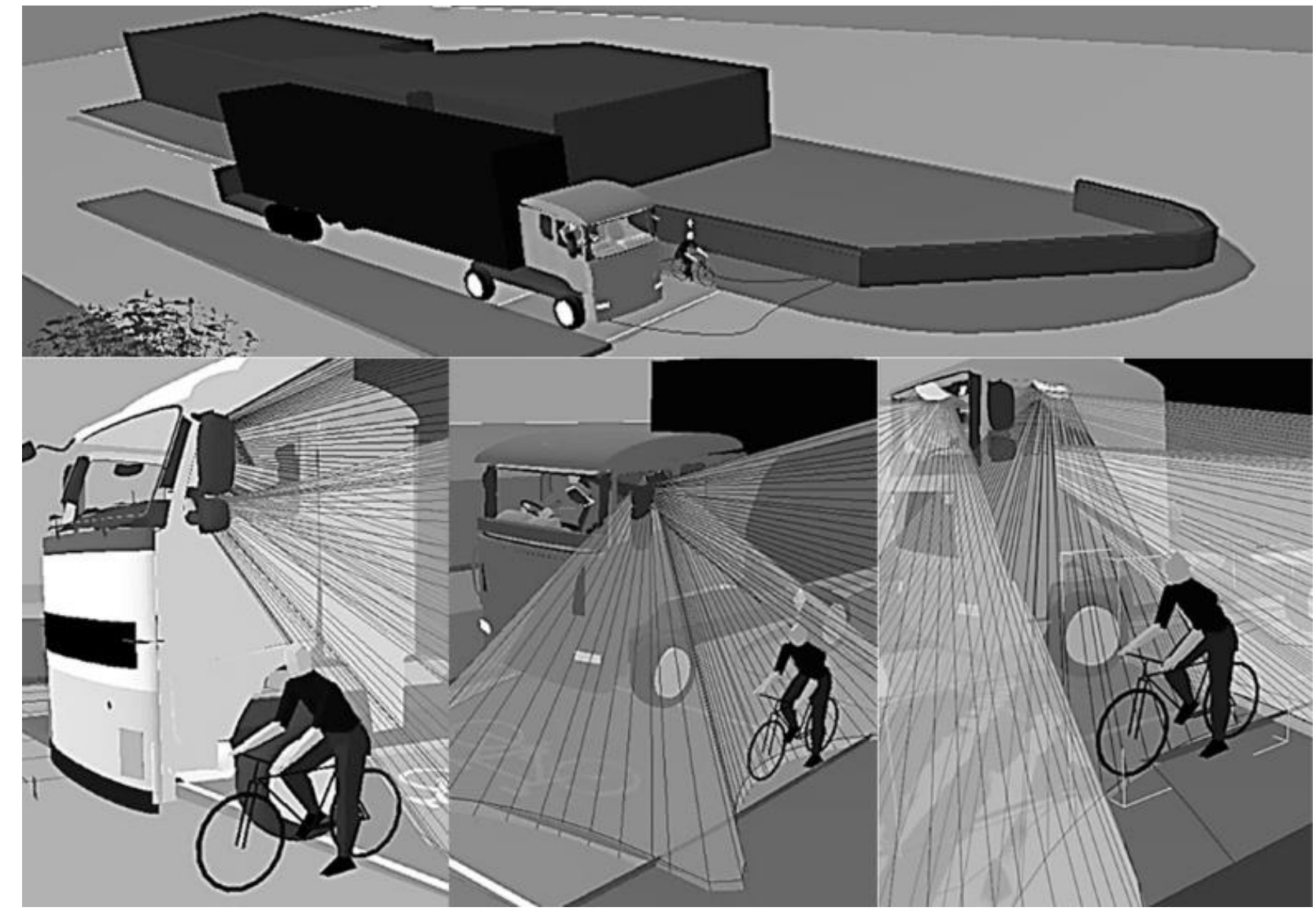

Figure 12. The vehicle junction that was modelled from the OTS data (top image) and the complete obscuration of the cyclist from the driver's vision for all three Category $\mathrm{N}_{3}$ vehicles

\subsection{Potential solutions to the issues identified in the results}


The analysis of the four scenarios performed as part of the research highlighted the potential benefits of allowing the driver of Category $\mathrm{N}_{3}$ vehicles to recognise the presence of other vehicles and vulnerable road users that are adjacent to the Category $\mathrm{N}_{3}$ vehicle, and outside of the current $2 \mathrm{~m}$ wide ground plane area that is specified in the standard UNECE Regulation 46. As part of the research performed potential solutions were analysed. This included technologies such as radar and ultrasound based detection systems (see work package 5 in the project report in Cook et al, 2011). In addition to this mirror based solutions were also explored. In order to remove the identified blind spot mirrors were researched that may offer appropriate characteristics. Due to the restrictions on radius of curvature it was considered that a physically larger mirror would be required. An aftermarket mirror that has the potential to fill the blind spot between the volume of space visible through direct vision, and the volume of space visible through current Class $\mathrm{V}$ mirrors was identified. The SPAFAX VM5 mirror has the same radius of curvature as standard Class $\mathrm{V}$ mirrors, but has a larger surface area in the vertical orientation. This mirror was tested in both real world (see section 6.3.7. in Cook et al. 2011) and DHM analyses and was shown to allow the identified blind spot to be eliminated. Figure 13 shows an example of the DHM analysis using the DAF XF 105 Category $\mathrm{N}_{3}$ vehicle.

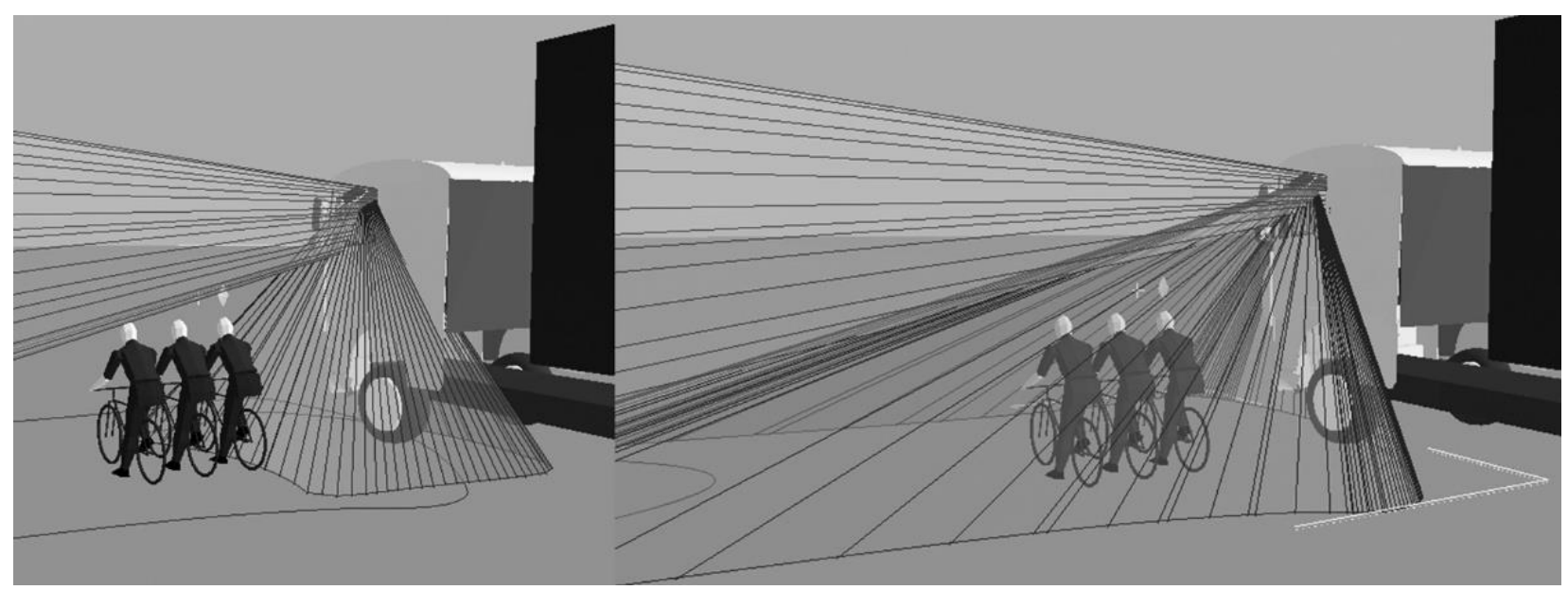

Figure 13. The left hand image shows the coverage of the standard Class $V$ mirror fitted to the vehicle and the right hand image shows the volume of coverage by the SPAFAX VM5 mirror.

\section{Discussion}

The results highlighted a key blind spot that exists with all of the tested Category $\mathrm{N}_{2}$ and $\mathrm{N}_{3}$ vehicles with the Class II, IV and V mirrors adjusted to meet UNECE Regulation 46. The tested category $\mathrm{N}_{2}$ vehicles were all considerably lower than the Category $\mathrm{N}_{3}$ vehicles as shown by the mounting height of the Class $\mathrm{V}$ mirror data shown in Table 5 . This allowed the cyclist and Category $\mathrm{M}_{1}$ vehicle visual targets to be seen by the tested driver using direct vision through the window as shown in Figure 9. However the blind spot in Category $\mathrm{N}_{2}$ vehicles does allow objects that are between $800 \mathrm{~mm}$ and $1180 \mathrm{~mm}$ high to be obscured from the driver at a location that is $2 \mathrm{~m}$ from the side of the cab as shown in Table 5. To provide context, $1180 \mathrm{~mm}$ is the mean stature of a six year old UK female (Adultadata, 1998).

The Category $\mathrm{N}_{3}$ vehicles that were tested produced larger blind spots than the Category $\mathrm{N}_{2}$ vehicles as shown in Figure 10. The results for the analysis of side swipe accidents 
highlighted variability between vehicles in terms of the proportion of the Category $M_{1}$ vehicle used as a visual target that can be seen by the LGV driver through either direct or indirect vision. The size of the blind spot depends upon the combination of the height of the driver's eye point above the ground, the size and radius of curvature of the mirrors, and the shape of the window apertures. For example, the SCANIA R420 showed the smallest blind spot size of the three Category $\mathrm{N}_{3}$ vehicles in terms of the proportion of the visual targets that can be obscured (see Figure 10). It had the lowest eye height above the ground, the largest Class V mirror configuration in terms of area of coverage (see Table 6), combined with a lower bottom edge of passenger window above the ground than the other vehicles. This allowed more to be seen by the driver through a combination of direct and indirect vision.

The results for the analysis of scenario 7 which analysed cyclist visibility highlighted that the Category $\mathrm{N}_{2}$ vehicles analysed allowed visibility of at least the head and shoulders of the cyclist visual target object for a 99\%oile driver. The Category $\mathrm{N}_{3}$ vehicles all had the potential to obscure a single cyclist placed at least $2 \mathrm{~m}$ from the side of the cab.

\subsection{Mirror based solutions to the identified blind spot}

The analysis of the SPAFAX VM5 mirror demonstrated that the blind spot can be removed through an alternative Class $V$ mirror design. Table 6 shows the dimensions of the SPAFAX VM5 in comparison to the Class V mirrors on the six vehicles that were tested. The 'Height' dimension allows improved lateral coverage. Table 6 shows that the difference between the mirror height for the analysed Category $\mathrm{N}_{3}$ vehicles and the SPAFAX mirror ranges from $5 \mathrm{~mm}$ for the DAF XF 105 mirror, to $25 \mathrm{~mm}$ for the Volvo 480 . It was therefore considered to be feasible to increase the size of Class $V$ mirrors to match or exceed the height of the SPAFAX mirror.

\begin{tabular}{lcccccccc}
\hline $\begin{array}{l}\text { Class V mirror } \\
\text { dimensions }\end{array}$ & $\begin{array}{c}\text { Category } \\
\mathbf{N}_{2} \text { DAF } \\
\mathbf{4 5}\end{array}$ & $\begin{array}{c}\text { Category } \\
\mathbf{N}_{2} \text { Iveco } \\
\text { Eurocargo }\end{array}$ & $\begin{array}{c}\text { Category } \\
\mathbf{N}_{2} \\
\text { Renault } \\
\text { MIDLUM }\end{array}$ & $\begin{array}{c}\text { Category } \\
\mathbf{N}_{3} \\
\text { SCANIA } \\
\text { R420 }\end{array}$ & $\begin{array}{c}\text { Category } \\
\mathbf{N}_{3} \text { Volvo } \\
\mathbf{4 8 0}\end{array}$ & $\begin{array}{c}\text { Category } \\
\mathbf{N}_{3} \text { DAF } \\
\text { XF 105 }\end{array}$ & $\begin{array}{c}\text { SPAFAX } \\
\text { VM5 }\end{array}$ \\
\hline Width & $(\mathrm{mm})$ & 245 & 255 & 245 & 305 & 275 & 305 & $\mathbf{2 8 2}$ \\
Height & $(\mathrm{mm})$ & 145 & 155 & 145 & 175 & 160 & 180 & $\mathbf{1 8 5}$ \\
$\begin{array}{l}\text { Radius of } \\
\text { curvature }\end{array}$ & $(\mathrm{mm})$ & 300 & 300 & 300 & 300 & 330 & 450 & $\mathbf{3 0 0}$ \\
\hline
\end{tabular}

Table 6. The dimensions of the Class V mirrors associated with the tested vehicles and the SPAFAX VM5 mirror

\subsection{Changes to regulation on the basis of the research output}

The results from the project were used by the author to specify an amendment to the definition of UNECE Regulation 46 at the request of the UK Department for Transport. This amendment specified that the area of the ground plane that should be visible to the driver of Category $\mathrm{N}_{3}$ vehicles should be increased laterally from $2 \mathrm{~m}$, to $4.5 \mathrm{~m}$ (see Figure 14). This was defined to allow the blind spot that was identified in the research project to be eliminated in situations where cyclists and other vulnerable road users are further than $2 \mathrm{~m}$ 
laterally from the passenger door of the LGV. The proposed amendment also included an increase in the visible area forward of the driver's ocular points to $3 \mathrm{~m}$. This was proposed to allow category $M_{1}$ vehicles to be visible to the LGV driver in the Class V mirror based upon the vehicle positioning in the side swipe scenario. The proposed amendment was presented by the author acting as the 'UK expert' to the UNECE (United Nations Economic Commission for Europe) GRSG committee at the 100th meeting in April of 2011. This committee comprises of national representatives for each European country and vehicle manufacturers. The amendment was adopted by this committee at the 102nd GRSG meeting in April of 2012 (UNECE 2011). The amendment has been applied to new vehicle registrations in Europe from July of 2015.

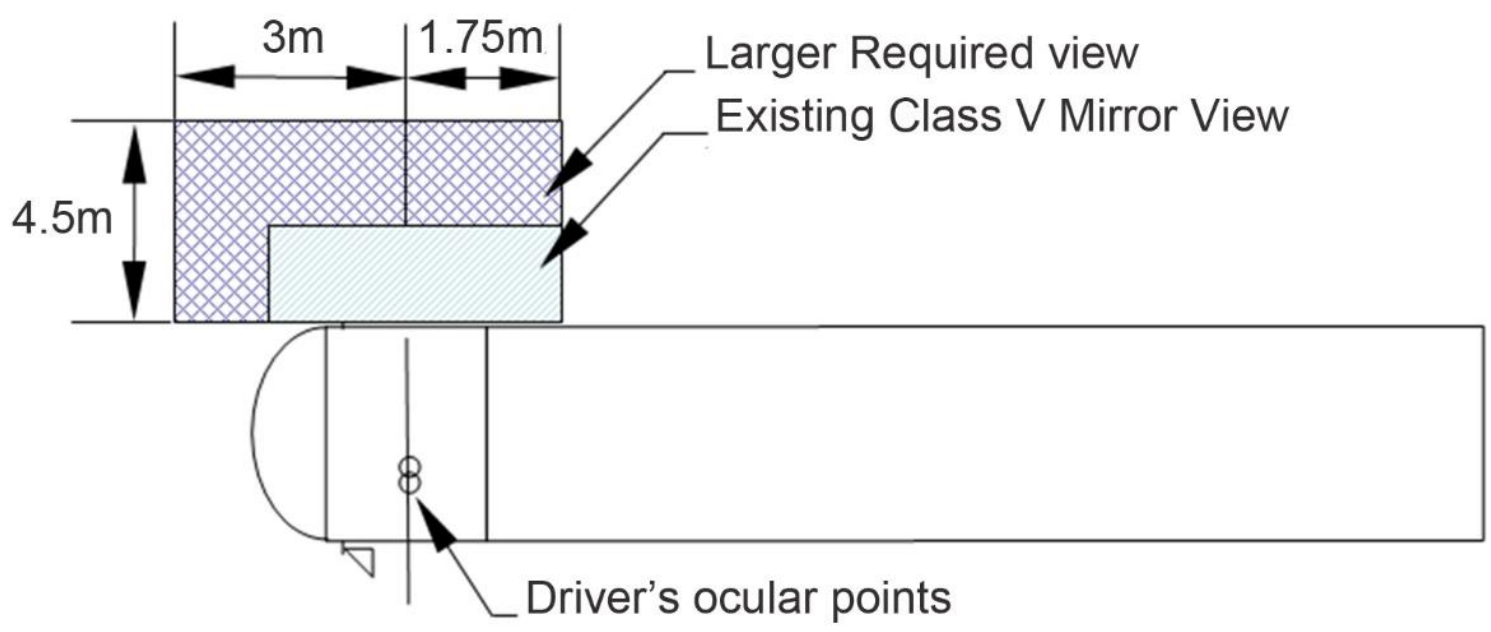

Figure 14. The changes to the required field of view proposed at the 100th GRSG meeting with the aim of removing the identified blind spot

\subsection{The benefits of DHM volumetric projection of windows and mirrors}

The introduction provided references to previous research which has explored the modelling of direct and indirect vision. The research presented by Dodd (2009) involved real world testing of mirror coverage by moving cones on the floor around the vehicle to edge of the mirror view as seen from the drivers position. The use of seven cones to model one mirror compares to the 100 data points that describe the shape of the edge of the Class V mirrors used in the SAMMIE DHM system. The effective increased resolution that is possible through digital means produces more accurate results compared to using cones to define the limits of mirror visibility. In addition, the digital techniques allow the exploration of potential solutions as demonstrated in Figure 13 which requires reduced time for setting up the analysis and allows a number of eye locations to be explored rapidly when compared to real world testing.

The work reported by Tait \& Southall (1999) involved the use of the SAMMIE DHM system in the identification of blind spots directly in front of LGVs. This work used direct vision in the identification of blind spots, and presented the projection of mirror coverage in two dimensional plan views only. The ability of the new projection technique developed to support the research reported here to visualise the volume of space that is visible to the driver through mirrors and windows was a key factor in the identification of the blind spot shown in Figure 10. 


\subsection{Further research}

The project has highlighted further research which is required. The variability in the results between the three tested Category $\mathrm{N}_{3}$ vehicles has been attributed to a number of variables associated with the vehicle design. Further DHM testing of a wider range of vehicle designs could quantify the variability of design features which contribute to the size of blind spots, with the aim of producing design guidelines for LGV vehicle designers which foster a reduction of blind spots.

The task of driving an LGV requires the driver to establish situational awareness of the location of VRUs and vehicles in close proximity to the cab using a combination of indirect vision through six mirrors, and direct vision through multiple windows. There has been no research into the strategies that are used by LGV drivers to perform this task. Sodhi (2002) established that the mean 'eyes off road time' required to look at a Class III mirror (rear view mirror) in a passenger car is 0.96 seconds with a mean eye movement time of 0.32 seconds. To provide an indication of the difficulty that LGV drivers face these figures could be applied to the visual scanning of six mirrors resulting in a task time of 5.76 seconds. If it takes over five seconds to scan six mirrors there is the potential for the situation to have changed in the first mirror that is scanned by the time that the last mirror is scanned. Research is required which quantifies the actual task time and examines the mirror use strategies adopted by LGV drivers utilising a portable eye tracking system. Whilst it is valuable to remove blind spots that exist by improving mirror designs, the difficulty in scanning multiple mirrors in high workload situations has the potential to contribute to accidents.

\section{Conclusions}

The research explored the prevalence of accidents that are associated with Category $\mathrm{N}_{2}$ and $\mathrm{N}_{3}$ vehicle blind spots. The accident scenarios that were identified were explored using Digital Human Modelling with a volumetric approach, combined with real world testing. The blind spots that were identified in the research have been shown to have the potential to be a causal factor in the accident scenarios. The research has highlighted the need to expand the volume of space that is visible to the drivers of Category $\mathrm{N}_{2}$ \& $\mathrm{N}_{3}$ vehicles. The amendment to the UNECE Regulation 46 that was a result of the described research has the potential to reduce accidents where vehicles and other vulnerable road users occupy the space that is adjacent to the cab of the Category $N_{2} \& N_{3}$ vehicles, but further than $2 \mathrm{~m}$ from the side of the vehicle.

\section{References}

Adultdata.1998. The handbook of adult anthropometry and strength measurements - data for design safety. eds. L. Peebles and B. Norris. Department of Trade and Industry.

Cook, S., Summerskill, S., Marshall. R., et al., 2011. The development of improvements to drivers' direct and indirect vision from vehicles - phase 2. Report for Department for Transport DfT TTS Project Ref: S0906 / V8. Loughborough: Loughborough University. 
Cuerden, R., Pittman M., Dodson, E. and Hill, J., 2008. The UK On The Spot Accident Data Collection Study - Phase II Report. Department for Transport Road Safety Research Report No. 73.

Dodd, M., 2009. Follow up study to the heavy goods vehicle blind spot modelling and reconstruction trial. Transport Research Laboratory. Department for Transport.

Ehlgen T., Pajdla T., Ammon, D. Larue, C. \& Giguere, D., 1999. 'Eliminating blind spots for assisted driving', IEEE Trans. Intell. Trans. Syst., 2008, 9, (4),pp. 657-665

FARO, 2015. http://www.faro.com/products/metrology/faroarm-measuring-arm/overview (accessed 10/06/15)

Hill J.R., Cuerden R.W., 2005. Development and Implementation of the UK On the Spot Data Collection Study - Phase 1. Department for Transport Road Safety Research Report No. 59.

Lenard, J., R. Danton, M. Avery, A. Weekes, D. Zuby and M. Kühn., 2011. Typical pedestrian accident scenarios for the testing of autonomous emergency braking systems, ESV paper no. 11-0196.

Low, J.L., 1976. The reliability of joint measurement. Physiotherapy 62:227-229

Marshall, R., Summerskill, S. and Cook, S., 2013. Development of a volumetric projection technique for the digital evaluation of field of view. Ergonomics, 56 (9), pp.1437-1450.

Martinez, W.L. and A.R. Martinez., 2005. Exploratory data analysis with MATLAB®, Chapman \& Hall, London

MIRA, 2015. http://www.mira.co.uk/ (accessed 10/06/15)

Porter, J. M. and Stern, M. C., 1986. A technique for the comparative assessment of external visibility characteristics in road vehicles, in A. G. Gale et al. (eds), Vision in Vehicles (Amsterdam: Elsevier), 313 - 322.

Porter, J. M., R. Marshall, M. Freer., 2004. SAMMIE: A Computer Aided Ergonomics Design Tool. In Working Postures and Movements, Tools for Evaluation and Engineering, eds. Delleman, N, Haslegrave, C, Chaffin, D. pp. 454-470. CRC Press.

PTC, 2015. http://www.ptc.com/product/creo/proengineer (accessed 10/06/2015)

Romesburg, H.C., 2004. Cluster analysis for researchers, Lulu Press, North Carolina.

Rothstein J.M., Miller P.J., Roettger R.F., 1983. Gonio-metric reliability in a clinical setting: Elbow and knee measurements. Physical Therapy. 63 pp. 1611-1615

Skyving, M., Berg H-Y. and Laflamme, L., 2009. A pattern analysis of traffic crashes to older drivers, Accident Analysis and Prevention 41, pp. 253-8. 
SAE J1100, 1995. Motor Vehicle Dimensions. SAE J1100. Society of Automotive Engineers Standard.

Sodhi, M. \& Reimer, B., 2002. Glance analysis of driver eye movements to evaluate distraction. Behavior Research Methods, Instruments, \& Computers. 34 (4), 529-538

Tait, R. \& Southall, D., 1999. Drivers' field of view from large vehicles. Phase 3 Report. http://hdl.handle.net/2134/549 (accessed 10/06/15)

UNECE 2011. http://www.unece.org/trans/main/wp29/wp29wgs/wp29grsg/grsginf102.html. See GRSG-102-29-Rev.1 - (United Kingdom) Adopted amendment of ECE/TRANS/WP.29/GRSG/2010/29/Rev.1 (Regulation No. 46) (Accessed 19/06/2015) UNECE Regulation 46., 2009. Uniform Provisions for Devices for Indirect Vision and of Motor Vehicles with Regard to the Installation of these Devices. UN ECE Vehicle Regulations. 